\title{
( UN) EXCEPTIONAL TRAUMA, EXISTENTIAL INSECURITY, AND ANXIETIES OF MODERN SUBJECTHOOD: A PHENOMENOLOGICAL ANALYSIS OF ARBITRARY SOVEREIGN VIOLENCE
}

\author{
SABEEN AHMED \\ Vanderbilt University
}

\begin{abstract}
Traumatic events call into question basic human relationships. They breach the attachments of family, friendship, love, and community. They shatter the construction of the self that is formed and sustained in relation to others. They undermine the belief systems that give meaning to human experience. They violate the victim's faith in a natural or divine order and cast the victim into a state of existential crisis.

Judith Herman, Trauma and Recovery
\end{abstract}

It is thanks largely to Giorgio Agamben's work on the "state of exception" that questions of state sovereignty and state violence, of who is protected and who is excluded, and of the margins and failings of law in times of emergency have dominated certain strands of political philosophy in the post-9/11 world. The decision on the "exception"-originally theorized by Carl Schmitt as the emblematic mark of sovereignty - has, on Agamben's account, increasingly come to inform the organizational core (and the political reality) of sovereign and state power, and has gone from proving the rule to establishing the rule. The decision, in other words, has become "a technique of government rather than an exceptional measure," and as such the normalized logic of modern governmentality (Agamben 2005, 6-7, emphasis added). And if modernity is marked by the normalization of the logic of the exception, then it is also marked by the normalization of "unlimited authority" and the monopoly of sovereign violence (Schmitt 1985, 12). Unique to the sovereign decision of today is that "it radically erases any legal status of the individual, thus producing a legally unnameable and unclassifiable being" (Agamben 2005, 3). However, insofar as "[t]he state of exception thus ceases to be referred to as an external and provisional state of factual danger and comes to be confused with juridical rule itself," there are increasingly entire populations of subjects who have, for the sake of the purity of the state, become excluded from political protection and thereby acutely vulnerable to state violence (Agamben 1998, 168). 
Influential though this reading has been, the conceptual framework of the "exception" crucially fails to account for the way in which such violence is felt under conditions of normalized, extralegal sovereign power. In other words, it is precisely when we accept that modernity is characterized by the state of exception turned rule without interrogating the actual operation of the normalized "decision" that we are unable, in the words of Judith Butler (2004), to account for the ways in which power "functions differentially, to target and manage certain populations, to derealize the humanity of subjects who might potentially belong to a community bound by commonly recognized laws" (68). This article accordingly problematizes the "exception" framework for precluding an analysis of the very experience of sovereign violence, due to its identification of the sovereign "decision" as a fundamentally ontologizing force that problematically renders bare life "a condition to which we are all reducible" (67, emphasis added). The approach I put forward here is predicated on a new understanding of sovereign power based not on a "decision" which renders all subjects "bare," but rather on the exercise of arbitrary violence to which different subject-populations are vulnerable to varying degrees. Perhaps more importantly, however, such a critical phenomenological articulation of sovereign violence can attend to the existential phenomenological consequences once the structures that make possible its exercise are dismantled or overcome. ${ }^{1}$ To this end, I conclude with a meditation on the traumatization resulting from persistent and pervasive anxiety by turning to narratives of subjects living in spaces where arbitrary sovereign violence is particularly acute.

Importantly, I do not suggest that we altogether abandon the conceptual framework of the exception; indeed, there is much in the theory of the exception that is valuable to my analysis and upon which I draw at various points in this article. My critique is therefore one of sufficiency: if we aim to theorize modern political violence and exclusion - and more importantly, if we aim to bring to light the experiences of the most marginalized, most liminal, and most precarious - it is not enough simply to articulate the grid of intelligibility of how sovereign violence is realized in institutions and norms, not enough to identify where exclusion takes place and how subjects are rendered in these places, not enough to simply state that "we are all virtually homines sacri" (Agamben 1998, 115). Instead, we must rethink contemporary political space as a horizon comprised of modalities which contour the lived experiences and conditions of possibilities of various subjects therein, rather than as demarcated, exceptional or extralegal regions which ontologize subjects into generalized categories of "bare life." By thus looking at both the mechanisms that make possible arbitrary sovereign violence as well as survivor accounts of those who have experienced such violence firsthand, I propose a new understanding of modern subjecthood as one of existential insecurity as a result of pervasive anxiety under conditions of arbitrary sovereign violence.

\footnotetext{
1 "Critical phenomenology," as I understand it, is the utilization of the classical phenomenological emphasis on lived experience in tandem with an emphasis on the interpersonal nature of lived experience and the rearticulation of the "subject" as not only constituting of the world, but also constituted by the world. It is only such an interpersonal and mutually constituting nature of subjectivity that can account for, as thinkers like Frantz Fanon have shown us, the ways in which intersubjective and politicized contexts contour the conditions of possibility open to differently-constituted bodies. The hope, in so doing, is the possibility of making visible discrete sites of power and, as such, spaces for intervention in social and political struggles. As put beautifully by Gayle Salamon (2018), "if phenomenology offers us unparalleled means to describe what we see with utmost precision, to illuminate what is true, critique insists that we also attend to the power that is always conditioning that truth" (15).
} 
I.

FROM SOVEREIGN DECISION TO ARBITRARY VIOLENCE

Much of why Giorgio Agamben identifies the state of exception as nomos of modern politics is the emphasis on security in a state-centric global order that upholds state sovereignty as the highest political virtue. Arguably, the security paradigm has intensified immensely in the post-9/11 Western (and especially U.S.) world through the framing of terrorism as the biggest threat to secular, democratic life. In the undefined and ongoing "War on Terror," the U.S. has propagated the existence of a perpetual threat (against its territorial integrity, against its hegemonic imperialist aims, and against its dominance as a world power) as justification for taking exceptional securitization measures both inside the state (through heightened surveillance, vetting of "suspicious" persons, and racial profiling) and beyond (paradigmatically through drone warfare). Unique to the security paradigm is that, once threat has been woven into the fabric of political life as such, then the state need not identify a clear object of threat - the hallmark of Schmitt's sovereign decision - and instead is able to take any exceptional measure, at any time, in the name of self-preservation. A consequence of this new sovereign logic is a shift away from the sovereign decision toward the arbitrary exercise of sovereign violence.

What distinguishes "arbitrary" violence from violence simpliciter is that the violence is often unanticipated, unforeseeable, or unknowable in advance by those upon whom the violence is ultimately inflicted. My understanding of "arbitrary" here draws from Robert Barsky's (2016) characterization of "arbitrariness in law" (which itself is, he acknowledges, contextually and contingently indexed) as a counterpoint to legal discretion. Discretionary decision-making - characterized principally as some sort of reasoned evaluation - "has to be undertaken in a reasonable manner, consistent with the statutory powers of the agency in question" (20, emphasis added). Conversely, "arbitrariness" contains within it an element of unreasonableness, a characterization that falls in line with Timothy Endicott's (2014) description (also cited by Barsky) of arbitrary government as "a distinctive form of unreasonable government; it is a departure from the rule of law, in favor of rule by the mere will of the rulers" (49, emphasis added). What Endicott emphasizes is the lack of justification as a marker of this unreasonableness and, thus, of arbitrariness: "a decision is arbitrary," Endicott writes, "whenever the law itself ought to demand a justification other than the fact that the decision maker made it, and there is no such justification" (70).

Widely accepted by legal theorists such as Barsky and Endicott, "reasonable" justification may include reliance on past precedent, compliance with procedure, or grounding in reasoned discretion. However, as George Wright (2010) explains in the context of law, "a decision is often thought of as arbitrary when it is 'founded on prejudice and preference rather than on reason or fact," the former of which are often mired in systemic and ideological biases (847). Arbitrary political decision-making may thus include political decisions or policies that are motivated by the biases and whims of the relevant party, without appeal to past precedent, procedural norms, or reasonable evidence. ${ }^{2}$ Taking undocumented immigrants as the emblematic modern figure upon whom arbitrary law is applied, Barsky (2016) observes that their preemptive "undocumented" status allows law enforcement officials to stop, detain, or charge them by singling out individuals who bear the "mark" of the stereotyped "illegal alien," "by their skin color, their accent, their inability to speak the language of the host country or by their license or ID (or lack thereof)" (2). The strength of executive power under these circumstances is heightened when subjects are rendered "illegal" or, as Agamben (2005) states in the case of Guantánamo

\footnotetext{
${ }^{2}$ Barsky (2016) himself lists racism and xenophobia as possible dimensions of such biases (18).
} 
detainees, "legally unnameable and unclassifiable" (3).

Barsky's and Wright's recognition of the deeply prejudiced nature of arbitrariness is significant, speaking as it does to the reality that not all subjects are equally vulnerable to arbitrary sovereign power. Indeed, one of the biggest challenges to Agamben's theory of homo sacer is the perceived ahistorical and apolitical framing of victims of sovereign violence embedded within. Given Agamben's use of the Nazi camp as the emblematic site where bare life is produced (though he does, in a later work, recognize Guantánamo Bay as the "modern" camp), many postcolonial and critical race theorists have criticized Agamben's lack of historical and material contextualization of homo sacer. ${ }^{3}$ As Shampa Biswas and Sheila Nair (2010) note:

[e]ven if one accepts Agamben's argument that the camp may be the nomos of our present, the distribution of bodily vulnerability in that present is far from democratic and indeed remains profoundly asymmetrical. Understanding which bodies are at risk of exceptionalization through the logic of sovereignty requires us to be attentive to the workings of colonial power. (6)

Sensitive, too, to the racial politics driving immigration law in the United States and elsewhere, Barsky and Wright recognize that a constellation of sovereign practices - from executive orders to immigration and incarceration policies - as well as social discourses - regarding who "belongs" and who threatens the imagined or desired hegemony of the nation-state - today have left a host of racialized subjects at the mercy of arbitrary violence without any clear understanding of when (during daytime police checkpoints or nighttime raids), upon which subjects (which migrant communities, which subjects of color failing to comply by hegemonic standards of civility), and by whom (police, security personnel, TSA agents) sovereign power will be enforced.

Nevertheless, Barsky's and Wright's analyses of arbitrary law fall very much in line with Giorgio Agamben's (2005) reformulation of the space of exception as an "anomic space in which what is at stake is a force of law without law" (39). In traditional law, according to Agamben, "reference to the concrete case entails a "trial" that always involves [...] an enunciation whose operative reference to reality is guaranteed by the institutional powers" (39-40, emphasis added). What Agamben touches upon here is the necessity of discretion (as that which justifies the norm's application to a concrete particular) as a norm of the juridical sphere. This of course is a feature of law that even Aristotle foresaw, recognizing that the articulation of law - generalized principles - could never account for all possible cases, and the elevation of virtuous phronesis as critical for just legislation: "in the case of law," Agamben too writes, "the application of a norm is in no way contained within the norm and cannot be derived from it," and this is precisely why trial and due process become critical conduits for establishing justified application (40, emphasis added). It is in the state of exception where the justificatory link between law and its target of application becomes "impossible," the "threshold at which logic and praxis blur with each other and a pure violence without logos claims to realize an enunciation without any real reference" (40,

\footnotetext{
${ }^{3}$ Postcolonial and critical race-oriented critiques of homo sacer were, in the immediate aftermath of Homo Sacer's publication, widely circulated. One of the predominant criticisms launched against this figure was the de-contextualization of homo sacer from her historico-material context into a generalizable referent of victimhood and oppression. I myself have offered a critique along these veins (see Ahmed 2019), but recognize that an array of alternative readings of Agamben's "ontology" have emerged that aim to partially vindicate homo sacer from such critiques. Here, the work of Mathew Abbott (2014) is both indispensable and deeply persuasive, wherein Abbott suggests that "such criticisms depend in large part upon a category mistake" which fails to look at Agamben's ontology as deeply enmeshed with politics rather than an abstraction away therefrom (17).
} 
emphasis added). Just as in arbitrary law there is an unjustifiable departure from the rule of law, so too in the state of exception does the sovereign transcend the law in response to a supposed threat to the security of the State that law cannot foresee, abandoning logos in its wake.

If we take arbitrary sovereign violence as the defining characteristic of the normalized state of exception, then the prevailing consequence for vulnerable populations is a feeling of "fear and uncertainty" borne from not knowing when one will be targeted, precisely because there is "no rule of law upon which to rely" in terms of profiling potential "threats" (Barsky 2016, 150). Accordingly, members of such vulnerable populations live in a near-constant state of what some have called "ontological insecurity" and which I call existential insecurity generated by persistent anxiety. ${ }^{4}$ Once the status (whether in terms of legality or criminality) of entire populations hinges on the whims of executive forces, the ever-present possibility of being singled out leaves one temporally and spatially bereft of security. For these persons, "the object of danger or fear is either absent/non-identifiable, or in such a proximity that no reassurance can be offered" (Eklundh, Zevnik, and Guittet 2017, 5) and "[t] he perception of time and space becomes displaced by the modes in which anxiety operates and changes the socio-political landscape" (7).

In order to better assess how precisely anxiety takes shape "on the ground," so to speak, I turn now to a phenomenological rearticulation of the "state of exception" in order to highlight the existential consequences generated by arbitrary sovereign violence. It is the experiences of those who inhabit spaces of exception - in other words, those who are particularly vulnerable to arbitrary sovereign violence - that demand attention, and where the conceptual framework of the "state of exception" alone is insufficient. Importantly, my use of trauma studies here is not intended to diagnose vulnerable subjects as "suffering" trauma; rather, I suggest that trauma studies and affect theory can supplement our broader analyses of state and sovereign violence through its prioritization of affected and effected subjects rather than of oppressors or architects of violent practices. That being said, I also do not intend to suggest that affect theory and trauma studies should comprise the extent of our attention to vulnerable subjects; the next move, which lies beyond the scope of this paper, would be to amplify the mechanisms of resistance and perseverance that subjects possess and are able to employ in spite of inhabiting insecure spaces. ${ }^{5}$ The reorientation toward affect studies that follows, then, is only the first step in centering vulnerable subjects as subjects whose voices are essential for understanding the broader consequences of arbitrary sovereign violence.

\section{II.}

\section{ANXIOUS BODIES, TRAUMA, AND BEING-IN-THE-STATE OF EXCEPTION}

Architectural historian Anthony Vidler noted in 1993 that "the realms of organic space of the body, and the social space in which that body lives and works [...] no longer can be identified as separate" (84), but recognized too that "a theory of space, uncorrected by any dialectical relationship with history, has often hovered dangerously close to a metaphysics of place" (85). Understood in a Marxist register, "history" is the situatedness of beings, the contextual-

\footnotetext{
${ }^{4}$ Though there is arguably an existential dimension thereto, I distance myself from use of the term "ontological" insecurity here as my interest is not solely on categories of "self-identity" or the "precarity" of being, but also on the affective and phenomenological aspects of such precarity on the individual and interpersonal level. However, I do share in many of the foundational assumptions upon which ontological insecurity is grounded, such as the necessity of trust and "belief in the continuity, reliability, and consistency of oneself, other people, and things" needed for ontological security (Hewitt 2010, 511). For more on ontological insecurity, I direct the reader to Giddens (1991) and Young (2007).

${ }^{5}$ Isabell Lorey (2015) and Mariana Ortega (2016) are particularly insightful here.
} 
ized sociopolitical, cultural, and economic landscape in which beings come to be multifaceted subjects with overlapping identities. Taking up history in this distinctly materialist manner is not unfounded; Andrzej Zieleniec (2007) has emphasized the implicit role of space in Marx's historical materialism, as both a mode of production and context of consumption, and recognized that, "whether space is more or less experienced and emphasized as a barrier or a limit to reciprocity reflects an understanding of Marx's view of society as a set of relationships that link individuals" (7). Alongside these Marxist understandings of space as social and political arenas of sociality, the philosophical writings of Martin Heidegger, Maurice Merleau-Ponty, and Michel Foucault have, in recent decades, inspired critical phenomenologists to more deeply theorize about the relationship between body and space, recognizing a crucial existential dimension shaped by one's relation to space that delineates one's comfort in the world.

David Morris' The Sense of Space (2004) is a meditation precisely on this existential dimension, wherein he suggests that the fundamental situatedness of human motility - that which allows for the emergence of meaningful experience - is the "directed fit" that grounds all interactions between embodied consciousnesses and objects in the world:

... depth is constitutively differentiated as having a sense, a meaning for us, and it is we who make sense of that meaning; sensing is not a passive activity, it is an active, transitive activity that depends upon sustaining a difference and sameness that crosses body and world. Body and world are thus sensed to one another, their relation is constituted such that the two appear as having a directed fit, the sort of fit belonging to a glove that fits on one hand, but not the other. (24)

All perception, according to Morris, is thus a "matter of moving in the world in a limited way" - contoured, in other words, by our unique understanding of the spaces in which meaning has become sedimented over time (109). It is for this reason that familiar movements of objects and people fade into the background of our perceptual field - what Morris refers to as the "background unconcern" that is "sedimented with habitual meanings" (170) - and our attention is instead "grabbed by things that are "out of place"" (113).

Beyond sensory experience, however, our sense of space contains within it an affective or psychosocial dimension that bears on our feeling of comfort in the world; "[a]ffective depth," as Lisa Guenther (2015) writes in her phenomenological critique of solitary confinement, "marks the emergence and unfolding of meaningful space, space that matters to what Heidegger would call my Being-in-the-world" (242). It is this affective element - in both its individual and intersubjective modalities - that I refer to as the "existential" dimension of being-in-the-world and which serves as the ground of all of our phenomenological experiences of spatiality. And crucially, once the unfamiliar enters our perceptual field or we are thrown into a spatial situation we have not previously encountered - once we experience a disruption of familiar space, in other words - we experience not only a perceptual "shock" but an affective one as well.

Sara Ahmed has been a leading voice in contemporary affect theory, recognizing that geopolitical shifts - particularly in the increasingly multicultural West - challenge the longstanding norms and narratives that shape the social imaginaries and constructed identities of the "nation." The response, Ahmed suggests, has been the reorientation of "world-making" by dominant social groups (in the U.S., white social groups) to reassert a "politics of truth" that recognizes and secures their privileged status. Crucial to this world-making is the use of fear to manufacture identifiable objects of threat from which subjects can "[reestablish] distance 
between bodies" and make borders "by establishing objects from which the subject, in fearing, can stand apart, objects which become 'the not' from which the subject appears to flee" (Ahmed 2003, 388, 389). This has paradigmatically been accomplished by designating certain subjects (brown, ethnically Arab, Afghani, or Pakistani, of Muslim origin, etc.) "terrorists" that the sovereign, in the interest of its white subjects, uses to reassert itself as a beacon of freedom, liberal progressivism, and democratic self-fashioning.

Here the distinction between anxiety and fear is crucial, insofar as anxiety does not operate quite like the "affective political tool" of Ahmed's writings. For Ahmed (2014), fear "preserves only through announcing a threat to life itself," an announcement that in turn produces objects - determinate threats, in other words - that the state can then address through exclusion, containment, or elimination (64). Fear, then, works to preserve a designated "us"- which, for Ahmed in the context of the U.S., is the "white" world - and latches on to objects that (threaten to) "approach." In this way, fear becomes identity-producing or -sustaining - creating "the very effect of "that which I am not" (67) in order to mobilize and protect the (white) "bodies" that fear - due largely to the paradigm of security that has eclipsed (or perhaps, reoriented) the state's aims in the post-Cold War age. Rather than inspire the production of political collectivities - as is its function in, for example, the Hobbesian social contract - the language of fear now "involves the intensification of threats, which works to create a distinction between those who are 'under threat' and those who threaten" (72).

Anxiety, on the other hand, is an approach to objects - rather than, as with fear, "produced by an object's approach" - and manifests as the "detachment" from objects to which anxiety "sticks" (66). Anxiety is not unrelated to fear, but it does inspire in the anxious subject a unique relation to the world that fear does not, eroding the subject's sense of self and motility in a world that has become unpredictable, unknowable, and unsafe. Insofar as objects of fear can be eliminated, bypassed, or avoided, the looming threat characteristic of anxiety is not exhausted even after concrete manifestations of sovereign reprisals - either through deportation raids, drone strikes, or unpredictable police brutality - are carried out. In these instances, it is the unpredictability of sovereign violence itself that sustains the feeling of anxiety for bodies vulnerable thereto; to the extent that there is no identifiable object of fear for those at risk of experiencing arbitrary sovereign violence (a mirror of the lack of referent that for Schmitt necessitated the sovereign decision), there is no way for the vulnerable subject to flee or eliminate that which induces the anxiety and, consequently, anxiety comes to pervade all aspects of the subject's interactions in and with space. As Norma Rossi (2017) acutely observes, "anxiety is destined to remain below the surface once the crisis has passed, both in the form of past traumatic memory and possible future return" (127). Unlike fear, then, anxiety thus does not serve to preserve secure spaces, but renders space perpetually insecure.

Rossi's appeal to the language of "trauma" here tellingly illuminates a key dimension of persistent anxiety which is mirrored in Judith Herman's work on trauma. Herman (2015), professor emerita of psychiatry at Harvard Medical School, observes that "[i]t is not necessary to use violence often to keep the victim in a constant state of fear," but fear is rather "increased by inconsistent and unpredictable outbursts of violence" (77, emphasis added). Notably, Herman is here speaking of trauma caused by captivity in particular - drawing on the Nazi concentration camp as an extreme manifestation thereof - but, if the state of exception is everywhere becoming the rule, this may be reasonably extended to our conceptualization of the status of those living in spaces of arbitrary violence. Assumpta Ekeh's (2016) phenomenological analysis of trauma is further helpful here, which posits that "[b] eing involved in an unforeseen trauma is being thrown into the world in a particular way" (174, emphasis added). Understood in the language of "worlds," trauma "presents a loss of control over how reality is understood, severing the fundamental distinctions used by individuals to make sense of their surroundings" (Furtado 
2017,40 , emphasis added). In other words, the unpredictability of the security of one's space of inhabitance and the trauma generated thereby renders one's very existential relation to the world insecure.

Building on this theme, theorists and social scientists alike recognize that trauma often accompanies fundamental changes in a subject's relation to space and, as such, comfort in space, both with regard to material objects and other "embodied consciousnesses." Drawing on the Diagnostic and Statistical Manual of Mental Disorders (DSM) and the International Statistical Classification of Diseases and Related Health Problems (ICD) by the World Health Organization, Martin Endreß and Andrea Pabst (2013) outline five predominant symptoms of trauma "which have implications for interpersonal relationships" (97). Of the five, two include "alteration of spatial experience" and "alteration of self-awareness and perception of others" (97, 98). In their account of the phenomenology of violence as a "negation of sociality," Endreß and Pabst emphasize the interconnectedness of experiences of trauma and the destabilization of self and world.

A prime example is the reporting of Pakistani psychiatrists who have worked with survivors and civilians living in the Federally Administered Tribal Areas (FATA), the most unremitting site where drone strikes have taken place under the 2001 Authorization for the Use of Military Force (AUMF). ${ }^{6}$ The testimonies of survivors and witnesses indicate psychological insecurities not dissimilar from the "phenomenological disorder" described by Guenther or the "alteration" of social situatedness described by Endreß and Pabst:

Interviewees described emotional breakdowns, running indoors or hiding when drones appear above, fainting, nightmares and other intrusive thoughts, hyper startled reactions to loud noises, outburst of anger or irritability, and loss of appetite and other physical symptoms. Interviewees also reported suffering from insomnia and other sleep disturbances, which medical health professionals in Pakistan stated were prevalent. (83)

As Endreß and Pabst note in their analysis of social trust, " $\mathrm{t}$ ] he doubting of one's own perception combines with the finding that the social environment has lost its reliability ... [and] 'ontological security' is harmed or destroyed." This, Endreß and Pabst suggest, is "accompanied by [not only] a loss of trust in one's own abilities, but the perception of others, the perception of spaces, time, and situations is, at least, disrupted" (100). Quite simply, the ontological insecurity generated by the spatial disruption of the drone zone, as we can see through these firsthand accounts, engender forms of experience that are, as Serena Parekh (2013) says, rooted in "a separation from the common realm of humanity" (646). Perhaps most troubling, howeverand that which is most acutely absent in theories of the "exception"-is that the effects of these existential disruptions will linger well beyond the eradication of drone warfare or the subjects' departure from spaces where drone strikes have taken place. When speaking of drones' impacts on children, a mental health professional in the FATA voices her concern that:

... when the children grow up, the kinds of images they will have with them, it is going to have a lot of consequences ... People who have experienced such things, they don't

\footnotetext{
${ }^{6}$ This is a theme I have explored in greater detail elsewhere; see Sabeen Ahmed (2018) for a more thorough analysis of the phenomenology of space in the "drone zone" than what is presented here.
} 
trust people; they have anger, desire for revenge ... So when you have these young boys and girls growing up with these impressions, it causes permanent scarring and damage. ("Living Under Drones," 87)

Although sites where drone warfare are particularly acute spaces of arbitrary sovereign violence - arbitrary insofar as inhabitants have no way of knowing whether they are targets nor of when strikes will actually take place - they are by no means the only ones. Indeed, what I turn to now are accounts of U.S. citizens whose inhabitance in certain spaces - highly-concentrated immigrant communities, socioeconomically disadvantaged urban spaces, and, increasingly, the "intrusions" of subjects of color in white communities - render them particularly vulnerable to sovereign violence - incarceration, deportation, and execution - and induce a similar sense of existential insecurity.

What is distinctive about these spaces of exception, however, is that they are not spaces of exception for all subjects residing therein. This is a point beautifully expressed by Mariana Ortega, whose notion of the "multiplicity" of being attends to the varying degrees of "ease" that are contingent upon one's corporeal subjectivity and subsequent location in space and time. Drawing on Heidegger, Ortega (2016) characterizes the multiplicitous self as "being-in-worlds and being-between-worlds, a singular self occupying multiple social locations and a condition of in-betweenness" with a "sense of how she fares in worlds" on an existential register (64-65). It is precisely "being-in-worlds" that "constitutes an existential dimension of this self," insofar as "worlds are intertwined and stand in relation to powers with each other" rather than exist as static objects which organize subjects equally and homogeneously (65). This is largely why Ortega utilizes a phenomenological approach rather than an ontological one, to explain why it is that two subjects can exist in the same space without inhabiting the same "world." The space of exception similarly renders an "exceptional world" for some and not others, and it is to testimonies of those inhabiting these worlds that I now turn.

\section{III. NARRATIVES OF EXISTENTIAL INSECURITY AND THE NECESSITY OF PHENOMENOLOGY}

As Lisa Guenther (2013) eloquently states in her work on solitary confinement, life itself is "a struggle to maintain a meaningful, integrated, and open-ended relation to one's environment as a whole, including the other living beings with whom one shares a common Umwelt" (119). But what can we say of subjects who are prevented from developing a relation of comfort to the world altogether, whose daily existence is one of spatial - and thus, existential - insecurity, and whose experiences of trauma "overwhelm the ordinary human adaptations to life" (Herman 2015, 33)?

Fortunately, traumatization is increasingly acknowledged within philosophy and political theories as the realities of psychological- and neuro-atypicalities are destigmatized and normalized on the social scientific and medical levels. Concomitant to these shifts, however, has been a growing concern with "adverse childhood experiences" (ACEs) and their consequences on cognitive and behavioral development - issues that have yet to be adequately attended to in philosophical and political writings. As Judith Herman (2015) observes, "[e]arly life trauma affects the 'emotional brain,' the right brain, which develops rapidly in the first years of life and whose functions form the basis of human sociability" (257). However, given that more and more children are subject to different iterations of sovereign violence, much of which is arbitrary in 
nature, I suggest we look beyond discrete traumatic events - paradigmatically childhood sexual assault or abuse - toward the lasting developmental and interpersonal effects of persistent anxiety. It is for this reason that the cases I examine below focus on children, but in no way do I suggest that young adults or adults are not also vulnerable to similar psychosocial disorientations or destabilizations. Rather, if we understand the body as a "text" to the truth, then recognizing those most profoundly affected by arbitrary violence - children - may be particularly illuminating avenues for envisioning the futures of today's normalized spaces of exception.

Journalistic pieces and news articles paint the clearest pictures of these phenomenological realities, principally by publishing testimonies from parents that highlight the psychosocial consequences of children's suffering of arbitrary violence. Writing about a mother whose five-year -old son was shot during a Mother's Day Cookout, Stephen Crockett Jr. (2014) characterizes the interviewee's neighborhood in Richmond, Virginia as "infected":

[C] hildren from urban neighborhoods live in continual violence and therefore suffer from all of the symptoms that have been found in veterans once they return home from war. The big difference here is that the trauma is on a continuous loop because the violence is happening outside the front door. Even people who live with the trauma every day may underestimate its effect.

Other articles documenting life in the inner-city United States - populated predominantly by socioeconomically disadvantaged people of color - make similar analogies to veteran trauma, suggesting that there exists a widespread crisis of "urban PTSD" generated by the constant threat of violence; the crucial difference, of course, is that the anxieties generated by one's predominant world (rather than one that is singular and temporary, such as the battlefield) do not go away. As explained by Jen Christensen (2014) of CNN, "[i]f someone is exposed to prolonged, repetitive, or extreme trauma, the amygdala stays in alert mode. And the neuros, the pathways to this part of the brain, lose their ability to recover." And indeed, she adds, direct exposure to violence is unnecessary for subjects to develop this type of PTSD: "When there is a perception that there is disorder in a particular neighborhood, it causes some residents to suffer from PTSD" (emphasis added).

Though especially acute therein, these anxieties are not confined to urban spaces alone. Many Americans of color - and especially black Americans - have written about their experiences raising children to comport themselves in particular ways, avoiding gestures or behaviors - including playing with toy guns or wearing baggy clothing - that may indicate "criminality." Journalist Nikole Hannah-Jones (2018), for example, recounts not calling the police after a shooting incident in Long Island ("before Michael Brown [and] [b] efore police killed John Crawford III for carrying a BB gun in a Walmart or shot down twelve-year-old Tamir Rice in a Cleveland Park") because she "feared what could happen if police came rushing into a group of people who, by virtue of our skin color, might be mistaken for suspects." Jazmine Hughes (2014), writing during the early days of the \#BlackLivesMatter movement, remarks that this inability to trust in law enforcement "makes people afraid to have black babies, because they won't stand a chance." For her own part, Hughes states that, "[a]s a black woman, nothing will stop me from bearing and raising my future child, but nothing will stop me from raising them in fear."

Lisa Guenther has been a leading voice in illuminating the phenomenology of incarceration - principally in terms of solitary confinement - but we must remember that incarceration has harrowing psychosocial effects on the families and friends of those incarcerated. In par- 
ticular, children with incarcerated parents experience their own share of trauma, whether by bearing witness to a parent's arrest, having to adapt to a way of life void of essential emotional and economic support structures, or removal to foster care. In her recent article on cognitive behavioral therapy with children of incarcerated parents, Anna Morgan-Mullane (2018) observes that

[c] hildren can exhibit the emotional effects of parental incarceration through complex trauma-related stress symptoms such as isolating themselves from their peers, anxiety, struggling to form healthy interpersonal relationships, concentration problems, sleep difficulties, emotional withdrawal from family members, substance use or dependence, and significant feelings of shame and secrecy. If unaddressed, the impacts of these symptoms can often lead to longterm psychological and emotional functioning problems. (200)

Speaking to the "worlds" of these children, Morgan-Mullane adds that,

[c]hildren of incarcerated parents experience numerous sources of material and emotional insecurity. For example, children of incarcerated parents are more likely to receive public assistance, to experience interrupted phone or utility service due to non-payment, and to experience residential insecurity through missed mortgage and rental payments ... [and] a parent's incarceration can abruptly dismantle a family. (201)

Child separation is routinely addressed by trauma theorists as a profound source of chronic trauma, disruptive as it is of the necessary and "normal" attachment relationships established in infancy and which generate early feelings of "trust" in one's environment. Indeed, "[i] thas now become clear that the impact of early relational disconnections is as profound as the impact of trauma with a capital T" (Herman 2015, 263). Judith Herman and others call the effects of such relational disconnections "disorganized attachment," the primary causes of which are neglect in childhood, either through parental absence or forced separation.

Unsurprisingly, then, the Trump administration's infamous "zero tolerance" approach to detention and deportation has garnered scrutiny from those who recognize the lasting damage that "disorganized attachment" may precipitate. As testimonies reveal, the psychological aftermath of child detention - where many children report having been subject to "neglect, assault and other horrific abuse" (Ellis, Hicken, and Ortega 2018)- persists long after children have been reunited with their parents. Harvard Medical School pediatrics professor Charles Nelson describes the effects of parent-child separation as "catastrophic" for children, and petitions brought forth by the American Academy of Pediatrics, the American College of Physicians, the American Psychiatric Association, and "7,700 mental-health professionals and 142 organizations" warn of the future consequences of the "zero-tolerance" policy: "To pretend that separated children do not grow up with the shrapnel of this traumatic experience embedded in their minds is to disregard everything we know about child development, the brain, and trauma" (Wan 2018). There are, of course, myriad firsthand accounts that corroborate these professional edicts. Olivia Caceres, who was separated from her one-year-old-son at a legal point of entry in November of 2017, paints a harrowing and heartbreaking picture of life with her child after eighty-five days of separation: 
(My son) is not the same since we were reunited. I thought that, because he is so young he would not be traumatized by this experience, but he does not separate from me. He cries when he does not see me. That behavior is not normal. In El Salvador he would stay with his dad or my sister and not cry. Now he cries for fear of being alone.

[and] he continued to cry when we got home and would hold on to my leg and would not let me go. When I took off his clothes he was full of dirt and lice. It seemed like they had not bathed him in the 85 days he was away from us. (Desjardins, Barajas, and Bush 2018)

Testimonies like Olivia's are not unique in the Trump presidency, nor are they foreign to other minority groups' experiences of ontological insecurity in the United States, both before Trump and since. And for children of undocumented immigrants who themselves are U.S. citizens, the possibility that one or both parents will be arrested has disrupted routine life. Speaking of her son Joseph, a U.S. citizen, Maria (last name not provided) tells reporter Hilary Andersson (2017) that he "is now afraid to go to school at all": "I tell him: "It's OK love, you go to that bus," said Maria. 'But he's told me I'm scared I'm going to come back and you're not going to be in the house."”

Even prior to these more recent and extreme policy measures, the phenomenon of being a targeted, undocumented, or minority resident has brought with it a lasting existential burden:

With nearly 11 million undocumented immigrants nationwide and 17.6 million people with at least one undocumented relative, large communities are now experiencing anxiety about separation from their families. Some are having flashbacks to the violence they experienced in their home countries. Some are retreating into the shadows, afraid to drive, bring their children to school, or even seek medical care. (Rinaldi 2017)

A recent article by Widian Nicola, in which she offers a distinctly phenomenological analysis of her upbringing as part of an "illegal" Catholic-Palestinian immigrant family in the United States, troubles some of the stereotypes of "illegal immigranthood" by charting the difficult and often-unsuccessful attempts of such persons to obtain "legal" residency. When they first arrived in 1990, she writes, her parents "spent countless dollars on attorneys who offered false hope and stole their money only to leave our family wondering if we would have the chance to stop living under the shadows and fear of deportation" (Nicola 2017, 293). As she grew older, Nicola states that the very term "immigration"

. . . intimidated me, filled me with doom, and made me anxious. I lived with this pervasive fear of deportation and equated "immigration" with a "monster" that might come to get our family, and worse yet, hurt us ... This uncertainty and lack of permanency continues to impact life to this day. (294) 
Although Nicola was eventually granted DACA status, the threat of deportation ostensibly lifted, and her status as an "illegal immigrant" eliminated, "its ghost still haunted" her, making itself felt in her very corporeal being:

I knew cognitively that I was okay, but my body had still not caught up to the present reality of my now legal status ... As a child without the capacity to recognize, hold, and deal with my fears, I frequently disconnected from my body, mainly through eating. I did not have access, or, did not know I had access to, somatic resources to ground me in the awareness of my being, let alone my body ... My distorted, yet very real embodied experience, meant that the terror and anger I felt would continue to grow over the years. The anger manifested itself in a great deal of confusion about my identity and free will. (297)

For Nicola and others who have experienced or continue to experience unstable senses of spatial "at-home-ness," the psychological and social consequences of this perpetually insecure manner of being lingers well beyond any "correction" of ontological status.

By refocusing our attention on the existential consequences of inhabiting spaces of arbitrary violence, we find that theories of the exception fail to do justice to the realities of life in spaces where the exception has become the norm for many (raced) subjects. Even in literature on the traditionally theorized "spaces" of exception - the camp - there is little written on the phenomenological impact of camp inhabitance on the existential constitution of the subject; camp inhabitants are ontologized as homines sacri that are, for all intents and purposes, spatially-situated and contextually-bound. But what happens once the state of exception is eradicated, when the refugee camp is dismantled or liberated? For some, especially those who were born and raised in refugee camps, life outside of the camps is unimaginable. Asad Hussein (2016), budding journalist who was born in the Dadaab Refugee Complex in Kenya in 1996, wrote twenty years later that, "I belong to a generation of children who have been rendered stateless. I neither belong to Kenya, where I was born, nor Somalia, where my history begins. Sometimes, I say I am a child of UNHCR." Asad's testimony was a response to Kenya's most recent threat to demolish Dadaab, which has been the world's largest refugee camp since its establishment in 1991. Despite its "exceptional" status, the threatened existential disruption of Dadaab's eradication looms heavily for Asad and other camp residents.

Those who have more recently been rendered "stateless" - paradigmatically as a result of the Syrian catastrophe - have experienced devastating psychological effects of escaping harrowing conditions and losing the crucial interpersonal and existential capacity of self-determination in the face of European asylum practices:

The German Federal Chamber of Psychotherapists announced last year that more than 70 percent of refugees who reached Germany have witnessed violence; around 50 percent have experienced violence themselves. That figure holds for 40 percent of children; around a quarter saw violence against members of their family. As far back as 2013, UNHCR found that more than a fifth of Syrians in a refugee camp in Jordan experienced anxiety disorders, with 8.5 percent suffering from post-traumatic stress disorder. The German study found demand for psychotherapy among refugees just in Germany could be 20 times what is being delivered. (Herman 2016) 
Given the inadequacy of refugee camps' - and some host countries' - infrastructure and resources, the very living conditions of these "states of exception" leave researchers and theorists questioning what the future lives of their inhabitants could look like. According to Patricia Mouamar (2015), writing from Lebanon,

More than two-thirds of school-age refugees in Lebanon are being denied an education, either because they cannot afford the expenses or because they are forced to work to help support their families. In some areas, there are simply no schools available, or a lack of transport prevents children from attending classes. For these children, the future citizens and leaders of Syria, it's hard to maintain hope .... The truth, no matter how you view it, is that a whole generation of children is growing up displaced and educated. This will have real, long-term impacts, not just for them but for the future of their country.

These myriad accounts, distinct (and importantly so) as they are, demonstrate a shared feeling of perpetual unease, insecurity, and, fundamentally, anxiety. By drawing on these narratives, I have aimed to suggest that the effects of such spatially unstable living are profound in scope, and necessitate not merely ontological classification or structural accounts, but an understanding of the experiences of vulnerable subjects, articulated in their own words, in order to be captured fully.

\section{IV. EXISTENTIAL INSECURITY AS MODERN POLITICAL SUBJECTHOOD}

In a recent article for the New Yorker, Hua Hsu (2019) meditates on the "affective turn" in social and political theory, motivated in no small part by the "increasingly precarious times" and "sense of dawning futility" borne of a shifting global order propelled by 9/11. Hsu is here speaking to the general atmosphere in the United States of the Trump era, but we can imagine extending the sentiment beyond U.S. borders amid rising global populism, political polarization, the resurgence of extremism and fundamentalist views, and what seems to be a breakdown in the traditional narratives that allowed so many -including (and perhaps especially) the socially dominant - to make sense of their history, their identity, their existential security. If the era of the nation-state is approaching its end - as journalists and theorists alike increasingly hypothesize - we are witnessing the erosion not only of geopolitical boundaries, but of the economic, political, and cultural hegemonies that have constituted the existential stability of a certain spatial ordering of global society. This looming spatial disruption has kindled existential terror within privileged groups as well as oppressed populations, fueling ethno-nationalist populist movements and social justice movements alike. Beyond even the scholarly writings of affect theorists and political philosophers, it is telling that journalists and public figures increasingly characterize modernity as a "new age of anxiety" (Hsu 2019).

Taking a phenomenological approach is, of course, not the only way in which to engage critically with the social and political crises of our present day. It does, however, allow us to highlight the lived experiences of persons living in existential insecurity, so that we might better interrogate and do justice to the realities of these crises. As Widian Nicola (2017) suggests, phenomenological analysis offers a valuable parry against current social and political discourses concerning vulnerable subjects - whether undocumented immigrants, targets of drone strikes and other indiscriminate military strategies, refugees, socioeconomically disadvantaged persons, or those oppressed on the basis of other identity categories - that are "structured around 
a need to quantify the worth and value and/or threat of one group versus another," and which in turn "lead to conservations that attempt to defend the worthiness and credibility of the [subject] to stay or go, instead of attending to the underlying phenomenon at play" (294). At its core, phenomenology helps us move past concepts such as "bare life," "exception," and even "law" itself, to more effectively "lay bare" how the consequences of these ideas extend well beyond their abstract contours. From the amplification of deportations to extreme vetting, hyper-policing to technological surveillance, and degrees of political, ethnic, and religious factionalism not seen since the era of the World Wars, it is perhaps time to focus our attention on the phenomenological and existential crises of our current world if we hope for, and strive toward, a better future.

\section{REFERENCES}

Abbott, Mathew. 2014. The Figure of this World: Agamben and the Question of Political Ontology. Edinburgh: Edinburgh University Press.

Agamben, Giorgio. 2005. State of Exception. Translated by Kevin Attell. Chicago: The University of Chicago Press.

1998 [1995]. Homo Sacer: Sovereign Power and Bare Life. Translated by Daniel HellerRoazen. Stanford: Stanford University Press.

Ahmed, Sabeen. 2018. "From Threat to Walking Corpse: Spatial Disruption and the Phenomenology of 'Living Under Drones." Theory Eं Event 21(2): 382-410.

—. 2019. "Critiquing Agamben's Refugee: The Ontological Decolonization of Homo Sacer." In Refugees Now: Rethinking Borders, Hospitality, and Citizenship. Edited by Kelly

Oliver, Lisa M. Madura, and Sabeen Ahmed, 153-69. London: Rowman \& Littlefield.

Ahmed, Sara. 2003. "The Politics of Fear in the Making of Worlds." Qualitative Studies in Education 16(3): 377-398.

- 2014 [2004]. The Cultural Politics of Emotion. Edinburgh: Edinburgh University Press.

Andersson, Hilary. 2017. "Living in fear of President Trump's deportation drive." BBC, July 17. https://www.bbc.com/news/world-us-canada-40600552.

Barsky, Robert F. 2016. Undocumented Immigrants in an Era of Arbitrary Law. The Flight and the plight of people Deemed "illegal." Abingdon: Routledge.

Biswas, Shampa and Sheila Nair, eds. 2010. International Relations and States of Exception: Margins, peripheries, and excluded bodies. London: Routledge.

Butler, Judith. 2004. Precarious Life: The Powers of Mourning and Violence. London: Verso.

Christensen, Jen. 2014. "PTSD from your ZIP code: Urban violence and the brain." CNN. Last updated March 27. https://www.cnn.com/2014/03/27/health/urban-ptsd-prob lems/index.html.

CrockettJr., Stephen A. 2014. "PTSD in the Inner City Needs a Name that Respects Its Victims." The Root. Last modified 20 May, 2014. https://www.theroot.com/ptsd-in-the-innercity-needs-a-name-that-respects-its-v-1790875722.

Desjardins, Lisa, Joshua Barajas, and Daniel Bush. 2018. "My son is not the same’: New 
testimony paints bleak picture of family separation.” PBS NewsHour. Last updated July 6. https://www.pbs.org/newshour/politics/my-son-is-not-the-same-new-testimony-paintsbleak-picture-of-family-separation.

Ekeh, Assumpta. 2016. "Being-in-the-World of the Trauma Patient: A Heideggerian Perspective." Fournal of Trauma Nursing 23(3): 173-76.

Eklundh, Emmy, Andreja Zevnik, and Emmanuel-Pierre Guittet. 2017. "Introduction: The Politics of Anxiety." In Politics of Anxiety. Edited by Emmy Eklundh, Andreja Zevnik, and Emmanuel-Pierre Guittet, 1-14. London: Rowman \& Littlefield.

Ellis, Blake, Melanie Hicken, and Bob Ortega. 2018. "Handcuffs, assaults, and drugs called 'vitamins': Children allege grave abuse at migrant detention facilities." GNN. Last updated 22 June, 2018. https://www.cnn.com/2018/06/21/us/undocumented-migrant-chil dren-detention-facilities-abuse-invs/index.html.

Endicott, Timothy. 2014. "The Coxford Lecture: Arbitrariness." The Canadian Fournal of Law E. Jurisprudence 27(1): 49-71.

Endreß, Martin and Andrea Pabst. 2013. "Violence and Shattered Trust: Sociological Considerations." Human Studies 36: 89-106.

Forman, Erik. 2017. "Fight to Win!" ROAR: Reflections on a Revolution 5: 12-25.

Furtado, Henrique Tavares. 2017. "When Does Repression Become Political? The Use of the Language of Trauma in the Context of Violence and Anxiety." In Politics of Anxiety. Edited by Emmy Eklundh, Andreja Zevnik, and Emmanuel-Pierre Guittet, 37-56. London: Rowman \& Littlefield.

Giddens, Anthony. 1991. Modernity and Self-Identity: Self and Society in the Late Modern Age. Stanford: Stanford University Press.

Guenther, Lisa. 2013. Solitary Confinement: Social Death and its Afterlives. Minneapolis: University of Minnesota Press.

. 2015. "The Psychopathology of Space: A Phenomenological Critique of Solitary Confinement." In Medicine and Society, New Perspectives in Continental Philosophy. Edited by Darian Meacham, 233-50. Bristol: Springer.

Hannah-Jones, Nikole. 2018. "Taking Freedom: Yes, Black America Fears the Police. Here's Why." Pacific Standard. Last updated May 8. https://psmag.com/social-justice/why-blackamerica-fears-the-police.

Herman, Judith. 2015 [1992]. Trauma and Recovery: The Aftermath of Violence-From Domestic Abuse to Political Terror. New York: Basic Books.

Herman, Marc. 2016. "Why the Refugee Crisis is Just the Beginning." Takepart, June 24. http://www.takepart.com/feature/2016/06/24/refugees-ptsd.

Hewitt, Belinda Anne. 2010. “Ontological Insecurity.” In Encyclopedia of Identity. Edited by Ronald L. Jackson II, 511-12. Thousand Oaks: Sage Publications.

Hsu, Hua. 2019. "Affect Theory and the New Age of Anxiety: How Lauren Berlant's cultural criticism predicted the Trumping of politics.” New Yorker, March 18. https://www. newyorker.com/magazine/2019/03/25/affect-theory-and-the-new-age-of-anxiety.

Hughes, Jazmine. 2014. "What Black Parents Tell Their Sons About the Police.” Gawker, 
August 21. http:/ /gawker.com/what-black-parents-tell-their-sons-about-the-po lice-1624412625.

Hussein, Asad. 2016. "I grew up in the world's biggest refugee camp - what happens when it closes?" The Guardian, September 23. https:/ /www.theguardian.com/world/2016/ sep/23/kenya-dadaab-refugee-camp-what-happens-when-it-closes-asad-hussein.

"Living Under Drones: Death, Injury, and Trauma to Civilians from US Drone Practices in Pakistan.” 2012. International Human Right and Conflict Resolution Clinic (Stanford Law School) and Global Justice Clinic (NYU School of Law).

Lorey, Isabell. 2015. State of Insecurity: Government of the Precarious. Translated by Aileen Derieg. London and New York: Verso.

Morgan-Mullane, Anna. 2018. "Trauma Focused Cognitive Behavior Therapy with Children of Incarcerated Parents." Clinical Social Work fournal 46(3): 200-09.

Morris, David. 2004. The Sense of Space. New York: State University of New York Press.

Mouamar, Patricia. 2015. "Syrian refugees: 'A whole generation is growing up displaced and uneducated." The Guardian, March 15. https://www.theguardian.com/global-develop ment/2015/mar/15/syrian-refugees-a-whole-generation-is-growing-up-displaced-and-un educated.

Nicola, Widian. 2017. "Living 'Illegally': On the Phenomenology of an Undocumented Immigrant." Clinical Social Work Journal 45: 293-300.

Ortega, Mariana. 2016. In-Between: Latina Feminist Phenomenology, Multiplicity, and the Self. Albany: SUNY Press.

Parekh, Serena. 2013. "Beyond the ethics of admission: Stateless people, refugee camps and moral obligations." Philosophy and Social Criticism 40(7): 645-63.

Rinaldi, Tiziana. 2017. "The fear of deportation is making immigrants sick." The Week, September 1. http://theweek.com/articles/721638/fear-deportation-making-immigrants-sick.

Rossi, Norma. 2017. "The Politics of Anxiety and the Rise of Far-Right Parties in Europe." In Politics of Anxiety. Edited by Emmy Eklundh, Andreja Zevnik, and Emmanuel-Pierre Guittet, 121-38. London: Rowman \& Littlefield.

Salamon, Gayle. 2018. "What's Critical About Critical Phenomenology?” Puncta: Fournal of Critical Phenomenology 1(1): 9-17.

Schmitt, Carl. 1985. Political Theology: Four Chapters on the Concept of Sovereignty. Translated by George Schwab. Chicago: The University of Chicago Press.

Vidler, Antony. 1993. "Spatial Violence.” Assemblage (20): 84-85

Wan, William. 2018. "What separation from parents does to children: 'The effect is catastrophic."' The Washington Post, June 18. https://www.washingtonpost.com/national/ health-science/what-separation-from-parents-does-to-children-the-effect-is-catastrophic/2018/06/18/c00c30ec-732c-11e8-805c-4b67019fcfe4_story.html

Wright, R. George. 2010. "Arbitrariness: Why the Most Important Idea in Administrative Law Can't Be Defined, and What This Means for the Law in General." University of Richmond Law Review 44(2): 839-65. 
Young, Jock. 2007. The Vertigo of Late Modernity. London: Sage Publications.

Zieleniec, Andrzej. 2007. Space and Social Theory. London: Sage Publications 